\title{
POSTPRINT
}

\author{
Torben Heinze; Christoph Knill
}

\section{Analysing the differential impact of the Bologna Process: Theoretical considerations on national conditions for international policy convergence}

\begin{abstract}
Although there is a growing interest of policy makers in higher education issues (especially on an international scale), there is still a lack of theoretically wellgrounded comparative analyses of higher education policy. Even broadly discussed topics in higher education research like the potential convergence of European higher education systems in the course of the Bologna Process suffer from a thin empirical and comparative basis. This paper aims to deal with these problems by addressing theoretical questions concerning the domestic impact of the Bologna Process and the role national factors play in determining its effects on cross-national policy convergence. It develops a distinct theoretical approach for the systematic and comparative analysis of cross-national policy convergence. In doing so, it relies upon insights from related research areas-namely literature on Europeanization as well as studies dealing with cross-national policy convergence.
\end{abstract}

Keywords: Bologna Process; Comparative political science; Europeanization; Higher education research; Policy analysis; Policy convergence; Soft governance; Transnational communication

\section{Introduction}

For a long time higher education policy was not part of the European agenda. A deeper integration and collaboration in higher education policy or even the creation of a common European Higher Education Area (EHEA) seemed unthinkable, with European-wide

\section{T. Heinze (ه):}

Centre of European Integration, Otto-Suhr-Institute for Political Science,

Freie Universität Berlin, Ihnestr. 22, 14195 Berlin, Germany

e-mail: torben.heinze@fu-berlin.de

C. Knill:

Department of Politics and Management, University of Konstanz,

Box D 91, 78457 Konstanz, Germany

e-mail: christoph.knill@uni-konstanz.de 
cooperation being restricted to EU-mobility programmes (Beukel 2001). This picture changed considerably by 1999 . Twenty nine ministers responsible for higher education signed the Bologna declaration denoting the actual start of the so-called Bologna Process. With this document the ministers agreed on establishing an EHEA by 2010. Notwithstanding the legally-unbinding and intergovernmental character of the declaration, different reforms related to the process have been initiated in all of the signatory countries showing that "[...] governments have developed policies that fit the European agenda towards converging systems of higher education" (Huisman and Wende 2004, p. 355). Yet the observable degree of domestic change varies remarkably (e.g. BFUG 2005; LuijtenLub et al. 2005, p. 158; Witte 2006).

However, notwithstanding these findings, we still have rather limited knowledge on the extent to which the Bologna Process actually led to the convergence of national higher education policies. ${ }^{1}$ Moreover, there is a lack of systematic theoretical concepts that might account for the differential impact of the Bologna Process. To put it differently, we still do not know to what degree higher education policy is converging in the course of the Bologna Process, and what exactly the reasons for national differences in convergence effects are. So far, comparative and theoretically well-grounded analyses of higher education policy remain more the exception than the rule (Goedegebuure and Vught 1996; McLendon 2003; Slaughter 2001, p. 390). Even broadly discussed topics in higher education research like the potential convergence of European higher education systems suffer from a thin empirical and comparative basis for understanding the Bologna Process (Witte 2004, p. 406).

Against this backdrop, it is the objective of this article to develop a distinct theoretical approach for the systematic and comparative analysis of cross-national policy convergence, including the specification of testable hypotheses as well as respective independent variables (Goedegebuure and Vught 1996). This theoretical framework might serve as a starting point for future research on the differential impact of the Bologna Process.

In doing so, we begin by mapping national factors accounting for the differential national effects of the Bologna Process. In this regard several strands of research have to be considered, namely literature on Europeanization as well as insights and approaches of studies dealing with cross-national policy convergence. Based on this analysis, we develop a research design in a second step in order to analyse the interplay between international (i.e. the Bologna Process) and national explanatory variables in determining cross-national policy convergence.

\section{Mapping national conditions of cross-national policy convergence}

Research on Europeanization and on cross-national policy convergence deals with a diverse array of country-specific factors potentially affecting the effectiveness of

\footnotetext{
1 According to Hogwood and Peters "All policy is policy change" (1983, p. 25). From this point of view, the consideration of cross-national policy convergence allows for systematic comparisons of all kinds of policy change resulting in convergence and/or divergence. Therefore it should serve as a useful tool structuring comparisons on the direction and degree of policy change and the dynamics of higher education systems. In this regard, the case of the Bologna-Process seems particularly suitable for comparatively analysing the national conditions for international policy convergence, by means of transnational communication as a distinct causal mechanism. Whereas voluntariness and the stimulation of information exchange as well as learning are highlighted, other convergence mechanisms like the legal obligation to harmonize national policies play only a minor role. Also it is an international policy instrument that gives policy change a direction by actually aiming at cross-national policy convergence in higher education (Huisman and Wende 2004).
} 
convergence mechanisms (Holzinger and Knill 2005; Mastenbroek 2005; Tews 2002) encompassing both cultural and institutional, but also socioeconomic factors. ${ }^{2}$ To narrow down our analysis we focus on factors related to outputs of the political system only, i.e. the policies adopted by governments. We do not consider other implementation levels like outcomes as these may be influenced by many intervening variables (Holzinger and Knill 2005, p. 776). ${ }^{3}$ Within the Bologna Process governments act as agents directly involved in the implementation of the Bologna goals and subjects, while policy outcomes are only indirectly related to the causal mechanisms of convergence.

\section{Cultural factors}

Cultural factors belong to the standard repertoire in political science (e.g. Esping-Andersen 1990; Simmons and Elkins 2004). Despite a main focus on environmental, economic, and social policy, cultural factors have also been used for analysing higher education systems (e.g. Clark 1983; Vaira 2004). The explanatory power of cultural variables is mainly based on the assumption that cultural orientations are linked to specific patterns of interpretation and perception. Beliefs and expectations frame the behaviour and the interactions of actors taking part in the policy process, this way affecting policy outputs (Feick and Jann 1988, p. 210). Policy-specific discourses and political agendas are set within the broader cultural context of each country (Lenschow et al. 2005, p.801). Almond and Powell define political culture as the "[...] psychological dimension of the political system [...]. It consists of attitudes, beliefs, values, and skills which are current in an entire population, as well as those special propensities and patterns which may be found within separate parts of that population" (1966, p. 23). Different cultural dimensions have been discussed in the literature in order to describe cultural characteristics of countries as well as similarities between them, including factors like the religious structure, the level of secularization (Castles 1994), values (Inglehart 1989), or policy styles (Feick and Jann 1988).

In the literature on policy convergence several studies refer to the significance of cultural similarity in determining the impact and effectiveness of convergence mechanisms (e.g. Friedkin 1993; Strang and Meyer 1993). First, culturally similar countries are expected to share cognitions and perceptions concerning problems and their solutions (Lenschow et al. 2005, p. 801) leading to the adoption of similar policies. This corresponds to the idea that countries characterized by a similar political culture will tend to interpret and decode communication and its subjects likewise. Second, policy transfer might occur more easily between countries with strong cultural linkages. In their search for relevant policy models, decision-makers are expected to look at the experiences of those countries with which they share a close set of cultural ties (Strang and Meyer 1993). Notably in constellations characterized by high uncertainty about the consequences of policy choices, decision-makers are likely to imitate the practices of nations with which they share linguistic, religious, historical or other cultural linkages (Friedkin 1993; Simmons and Elkins 2004, p. 175).

Studies dealing with the differential impact of European integration on national policies also refer to cultural factors. In this context it is argued that political cultures characterized by

\footnotetext{
${ }^{2}$ Of course, the categories we describe a relatively broad and partly overlapping. Think about institutional approaches encompassing both structure as well as agency-related theoretical assumptions. Also cultural factors often mix up with institutions blurring the difference between these two categories of explanatory factors (Hall and Taylor 1996, p. 14).

${ }^{3}$ This also means that intra-institutional factors like organisational characteristics of higher institutions themselves can be excluded from our analysis.
} 
a consensual type of policy-making can adapt more easily to European policies than adversarial cultures, as oppositional political and social forces are better integrated in the implementation process (Héritier and Knill 2001, p. 258). In a similar vein, different families of nations or "worlds of compliance" regarding the adaptation and implementation of EUrequirements have been distinguished, denoting a "specific national culture of digesting adaption requirements" (Falkner et al. 2005, p. 319). ${ }^{4}$ Such classifications refer to stable patterns of how adjustment processes normally take place within different countries.

\section{Institutional factors}

Institutional approaches have a rather long tradition in policy-analysis. This popularity is mirrored by a variety of institutionalist approaches to be found in the present literature (e.g. Hall and Taylor 1996; Steinmo and Thelen 1992). The basic assumption is that institutionssimilar to cultural factors-influence actor's behaviour, e.g. by determining the options of action, forms of interaction as well as political resources available (Mayntz and Scharpf 1995). Institutions are generally conceived as formal organisation structuring the policy process, i.e. agenda-setting, opinion formation, mode of conflict resolution, formation of consensus, decision-making, and implementation (Seibel 1997, p. 363). This may include constitutions and laws, but also constitutional bodies like the government or parliaments, public organisation such as courts or intermediary organisations like parties or pressure groups.

A comprehensive approach encompassing structural as well as more actor-centred factors is pursued by Tsebelis who systematically analyses the institutional capacities to perform policy change $(1995,2002)$. According to this approach the probability for policy change and policy transfer respectively depends on the existence of veto players, i.e. "individual or collective actors whose agreement is required for the change of the status quo" (Tsebelis 1999, p. 593). Similar to Seibel's definition this may include individual actors like presidents or collective actors like chambers of parliaments or governing parties.

A further institutionalist argument is based on the expectation that policy convergence will be higher among states that share similar policy legacies (e.g. welfare state traditions). Institutionally similar countries should face lower costs of adjustment when borrowing policy models from each other. This means that the impact of convergence mechanisms will have stronger effects among states that are relatively similar in terms of existing institutional structures than among states characterized by highly different arrangements (Holzinger and Knill 2005, p. 791). Of course, institutional similarities are neither directly leading to policy convergence nor causing convergence. Rather the domestic institutional context influences the effectiveness of convergence mechanisms regarding the observable degree of cross-national policy convergence by structuring national decision-making. Accordingly, countries characterized by similar institutional configurations should adopt similar (transnational) policy items (e.g. Lenschow et al. 2005).

\section{Socioeconomic factors}

Cross-national policy convergence is not only affected by cultural and institutional factors but can also arise as a result of a country's socioeconomic characteristics. The expectation is that

\footnotetext{
4 The term 'compliance' refers to "the extent to which agents act in accordance with and in fulfilment of the conditions prescribed by international institutions" (Checkel 2000).
} 
in case of similar socioeconomic conditions countries are more inclined to react to a problem in a similar way and to adopt the same policy concepts (Bennett 1991; Holzinger and Knill 2005; Lenschow et al. 2005, p. 802). As studies on Europeanization have emphasized countries facing economic and similar policy-specific vulnerability generally adapt to European policies much more easily (Schmidt 2002, p. 898). The pressure for adoption and transfer of external models and policies does not only depend on policy-specific problems but may also result from general problems restricting the state's capacities to solve policy problems (Scharpf 1997). This may, for instance, relate to fiscal and economic restrictions stemming from regulatory competition (e.g. Drezner 2001), low economic growth or increasing national debts.

\section{Towards a research design}

After having elaborated on the national factors that potentially account for the differential domestic impact of convergence mechanisms, we can now apply these factors to the specific case of the Bologna framework. We intend to develop testable hypotheses on the relationship between the Bologna Process and country-specific factors determining the degree of crossnational policy convergence. The starting point of our considerations is based on the assumption that the Bologna Process and its impact on international policy convergence should essentially be described as a process of transnational communication. The term transnational communication relates to various different, but related mechanisms, including lesson-drawing, emulation, transnational problem-solving, and the promotion of policies by international organizations (Holzinger and Knill 2005, p. 782; Knill 2005, p. 770). ${ }^{5}$ All these mechanisms have in common that their function mainly rests on communication and the exchange of information between national and transnational actors as the determining cause for policy convergence (Ibid.). Correspondingly previous work on the Bologna Process is mainly linked to the analysis of soft governance (e.g. Martens et al. 2004; Veiga and Amaral 2006; Walter 2006) providing a common transnational platform for channelled communication and policy coordination between higher education actors. But what does the term 'Bologna Process' exactly mean?

In the first place, the notion of the 'Bologna Process' describes the implementation of the so-called Bologna Declaration in the signatory countries (Hackl 2001, p. 1) and the construction of an EHEA until 2010 - e.g. by introducing a two-tired curricula structure (Bologna-Declaration 1999). But the term also relates to a complex governance structure assuring its operation. This structure consists of representatives of the various Bologna countries $^{6}$ and the European Union and is advised by Europe-wide organisations. This encompasses university associations (e.g. European University Association), business (e.g. Union of Industrial and Employers' Confederations of Europe), the Council of Europe,

\footnotetext{
5 One has to keep in mind that regardless of the Bologna Process' (intergovernmental or supranational) character (Cerych 2002, p. 123; Neave 2003, p. 156) it does not matter what kind of actors decide on the course of the Bologna Process to explain its impact. More important for analysing its national effects are the underlying mechanisms causing national policy change and cross-national policy convergence.

${ }^{6}$ By now Albania, Latvia, Andorra, Liechtenstein, Armenia, Lithuania, Austria, Luxembourg, Azerbaijan, Malta, Belgium, Moldova, Bosnia-Herzegovina, Netherlands, Bulgaria, Norway, Croatia, Poland, Cyprus, Portugal, Czech Republic, Romania, Denmark, Russian Federation, Estonia, Serbia and Montenegro, Finland, Slovak Republic, France, Slovenia, Georgia, Spain, Germany, Sweden, Greece, Switzerland, Holy See, "the former Yugoslav Republic of Macedonia", Hungary, Turkey, Iceland, Ukraine, Ireland, United Kingdom, Italy, and the Republic of Montenegro.
} 
UNESCO/CEPES, and topic-orientated network organisations (e.g. European Network for Quality Assurance). Originally the participating ministers had only agreed on meeting at biannual conferences where the signatory states were supposed to present the state of implementation in their countries. Based on the adoption of additional goals and action lines, this rather spurious structure has been modified at the following ministerial meetings in Prague (2001), Berlin (2003) and Bergen (2005) to guarantee an adequate coordination and monitoring of the national adjustment process (Walter 2006; Witte 2006).

By now the formal structure of interaction entails not only the biannual ministerial meetings, at which the implementation of joint objectives is addressed and programmatic declarations and communiqués are unanimously determined by all full members, but also the so-called follow-up structure at the European level. At the heart of the follow-up structure is the Bologna Follow-up Group (BFUG), constituting a somewhat smaller group of representatives from the Bologna countries, the European Commission as well as the participating stakeholder organisations. The BFUG is formally responsible for the overall steering of the process and the preparation of the ministerial meeting (e.g. by drafting the Communiqué). This also entails concrete actions for the realization of the Bologna objectives by adopting a work programme as well as informing and reporting to the ministers in charge of higher education in the signatory countries. These general tasks are updated on each ministerial meeting with more concrete guidelines and operating instructions (e.g. to develop criteria for stocktaking).

Overall, the formal dimension of the Bologna Process itself has been strengthened since its start back in 1999. At the beginning it meant a rather loose coupling between different national and only a few transnational actors. By now Bologna has become a quite complex process that can be basically described as transnational higher education regime (Nagel 2006, p. 79; Walter 2006, p. 194) framing domestic beliefs and expectations (Knill and Lehmkuhl 2002; Veiga 2005, p. 10). This can in turn cause national policy change by changing preferences and strategies of national actors (Kohler-Koch 1999). The questions remains, what exactly is the outcome of this process? What does the concept of crossnational policy convergence imply?

The dependent variable: two types of policy convergence

Generally cross-national policy convergence can be defined as "the tendency of societies to grow more alike, to develop similarities in structures, processes and performances" (Kerr 1983, p. 3). However, in order to fully grasp the national impact of the Bologna Process and the convergence effects caused by the underlying mechanisms we consider two different types of policy convergence: sigma and delta convergence (e.g. Heichel et al. 2005).

Firstly, sigma convergence comes closest to the conventional understanding of convergence as the decrease in variation of domestic policies over time. In its classic form, a decreasing coefficient of variation (also known as dispersion index) coincides with policy convergence. However, the analysis of sigma convergence alone does only partially cover empirical realities as it does not necessarily address whether policy homogenization is synonymous with increasing proximity to a dominant policy model. Thus, delta convergence focuses on the minimization of the distance to an exemplary model over time, e.g. as promoted by an international organization or forerunner regarded as successful. Empirically, delta and sigma convergence often occur simultaneously. However, as different 


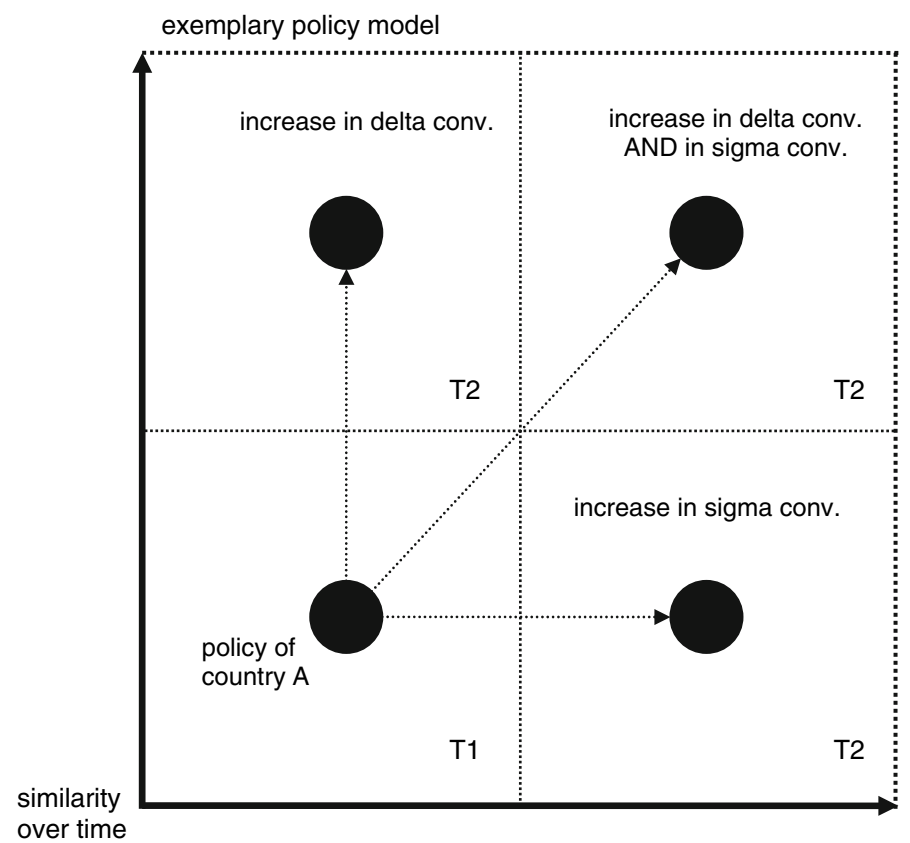

policy of other country or country group

Fig. 1 Sigma and delta convergence

points of departure can have decisive effects on convergent developments, policies may indeed move in the same direction, but from different points of origin, leading to the persistence of national peculiarities (see Bleiklie 2001, p. 27 for higher education policy). Or stated differently, countries may grow together (sigma convergence), but not necessarily move towards a common model (Holzinger et al. 2007) (see Fig. 1).

With reference to the Bologna Process, delta convergence refers to the adoption of European guidelines that have been elaborated at the Bologna platform, especially concerning degree structures and quality assurance systems (Bergen-Communiqué 2005) whereas the analysis of sigma convergence answers the question if the Bologna Process reflects a platform for information exchange that leads to similarity increases between national higher education policies surpassing the officially communicated and codified subjects.

The impact of country-specific variables on sigma convergence

To answer the question how country-specific factors impact on the harmonization of national policies over time (sigma convergence), we basically focus on the similarity of these factors between the countries affected by the Bologna Process. This refers to the underlying assumption that the national impact of convergence mechanisms like transnational communication is bolstered the more similar countries in terms of culture, institutions, and socioeconomic contexts are (Holzinger and Knill 2005, 2007; Lenschow et al. 2005). To put it differently, the more dissimilar the cultural, institutional, and 


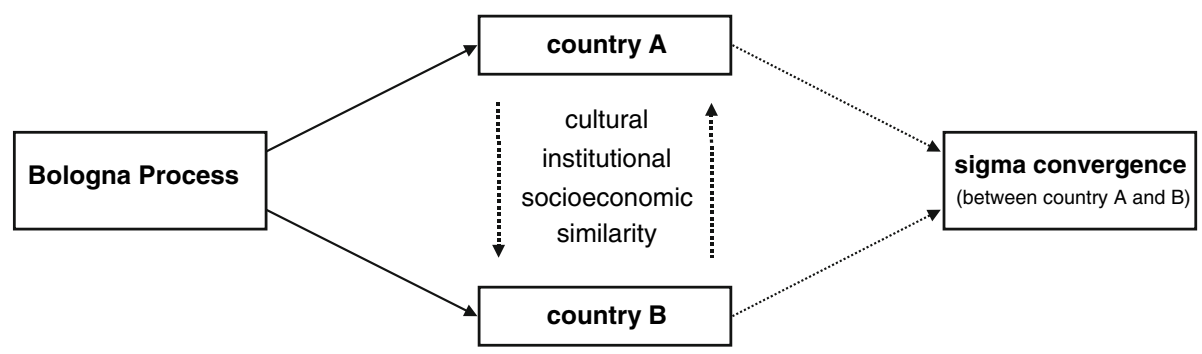

Fig. 2 Analytical framework on sigma convergence

socioeconomic characteristics of countries the less convergence between these countries can be expected under the influence of the Bologna Process (see Fig. 2). ${ }^{7}$

\section{Cultural similarity}

Concerning the effectiveness of transnational communication and its impact on crossnational policy convergence, we expect that countries characterized by high cultural similarity decode the arguments and suggestions communicated within the Bologna Process in a similar way hence introducing similar reforms (Neave 2003, p. 157). A lot of analysts dealing with higher education systems argue that universities are in a period of far-reaching transformation, which is exerting pressures for the reform and change of established national patterns of higher education systems (e.g. Dill and Sporn 1995; Enders 2002). This in turn creates situations of unprecedented uncertainty and a need for national reforms accentuating the relevance of cultural similarities. In that order we assume that the degree of convergence in higher education policies of culturally similar countries participating in the Bologna Process to be higher than in countries sharing fewer cultural linkages.

As already indicated in the previous section the bandwidth of relevant cultural dimensions is broad. Regarding the interpretation of the Bologna Process we argue that two levels of cultural similarity seem important. First, we expect that elementary cultural linkages in the form of a common language have to be considered if someone wants to analyse the impact of transnational communication.

Hypothesis 1a (linguistic similarity) The higher the similarity between the languages in $n$ countries, the more their higher education policies will converge under the influence of the Bologna Process.

Second, we have to deal with cultural factors directly referring to higher education policy and the university cultures characterizing each national higher education systems. In this context we expect that the extent to which the higher education systems of the signatory

\footnotetext{
7 As research on cross-national policy convergence is still lacking a systematic integration of theoretical arguments (Braun and Gilardi 2006; Braun et al. 2007) we do not discuss the potential relationship between the different variables. Such a task would need further (and more extensive) theoretical elaborations which we can not solve in such a short article. Surely one can expect cumulative interaction effects i.e. if a country is characterized by both cultural and institutional characteristics strengthening the domestic impact of the Bologna Process than we can expect even more convergence than in a case were only one of these factors is present.
} 
states are rooted in similar higher education traditions like the Humboldt, Napoleonic or Personal Development Model (see Gellert 1999) is of central importance.

Hypothesis $1 \mathbf{b}$ (university cultures) The higher the similarity between the university cultures in $n$ countries, the more their higher education policies will converge under the influence of the Bologna Process.

\section{Institutional similarity}

Most observers attempt to pinpoint institutional factors for explaining various reactions to the Bologna Process in the individual signatory states (e.g. Welsh 2004; Witte 2006). The reference to institutional factors underlines the impact of different national points of departure and pursued reform strategies which sustained national peculiarities filtering adjustment pressure and serving to uphold national differences in higher education (Bleiklie 2001, p. 26). Hence we expect that specific policies especially spread across those countries that are characterized by a high degree of institutional similarity, as national governments have a tendency to adopt only policies that are well in line with existing institutional structures (Knill 2001).

Regarding institutional factors that influence the likelihood of policy convergence between states two aspects seem of relevance for explaining the differential impact of the Bologna Process. The first factor relates to the degree of existing policy similarity across countries (Holzinger and Knill 2005, p. 790). We expect that countries featuring similar higher education policies (e.g. quality assurance systems) at the outset of the Bologna Process become even more similar under the impact of transnational communication than states that had pursued highly diverse policies. The opportunities for further convergence, however, might be restricted by saturation effects; i.e. a very high degree of pre-existing policy similarity (Holzinger and Knill 2007; Knill 2005).

Hypothesis 2a (pre-existing policy similarity) The higher the similarity in higher education policy between $n$ countries, the more their higher education policies will converge under the influence of the Bologna Process, except for constellations in which the degree of institutional similarity in $t_{\mathrm{o}}$ is already on a very high level.

A second institutional factor does not relate to the pre-existing policy similarity, but focuses on the programmatic level instead, i.e. the similarity of political programmes and policy preferences of national governments. The significance of agency-related factors like domestic preferences and beliefs, especially of national governments, for explaining crossnational policy convergence has been highlighted in convergence studies as well as in research on Europeanization (see Holzinger and Knill 2007; Mastenbroek 2005). Also studies dealing with higher education policy and the Bologna Process have referred to the importance of national strategies and preferences (e.g. Martens and Wolf 2006). Hence we also expect that the higher education policies of countries participating in the Bologna Process will converge to a higher degree if the programmes and preferences of their national governments for a specific higher education policy are in accordance to each other.

Hypothesis $2 \mathbf{b}$ (similarity of national government's policy preferences) The higher the similarity between the preferences of governments regarding higher education policy in $n$ countries, the more their higher education policies will converge under the influence of the Bologna Process. 
Socioeconomic similarity

Various factors have been considered, why an agreement on adjusting national higher education systems and building an EHEA within the framework of the Bologna Process was possible (see Neave 2003, p. 149; Vught et al. 2002, p. 108). Among them several socioeconomic factors were discussed, like the lacking competitiveness of most European higher education systems compared to most Anglo-Saxon universities (Hackl 2001; Huisman and Wende 2004), the growing importance of higher education regarding a country's general welfare, or the transformation towards a knowledge-based economy (Heidenreich 2003; Vught et al. 2002). In this context the policy models communicated on the Bologna platform have been developed as Europe's response to global pressures (Wende 2001; Wende and Huisman 2003).

In general, it can be expected that decision-making in the member states of the Bologna Process regarding higher education conforms the more similar the socioeconomic conditions in these countries are. First of all, socioeconomic similarities refer to policy-specific problems states are confronted with, including for example problems of brain-drain, low international reputation of national universities, low graduate outputs and low success rates, academic unemployment, or insufficient financial resources (Altbach 1998; Schimank and Stölting 2001; Teichler 1996). The dissimilar state of higher education systems results in a differing need for reforming higher education, facilitating or impeding policy change and the transfer of (transnational) policy concepts and best practice (see also Witte 2006, p. 93). In case of similar degrees of problem pressure between countries we can expect the Bologna Process to cause similar convergence effects. Certainly, problems in higher education differ between countries not only concerning the degree of problem pressure, but also regarding the specific nature of the problems. But despite the case sensitivity of policy-specific problem contexts we argue that it is especially the international competitiveness of national higher education systems that needs further consideration regarding the differential impact of Bologna Process (Hackl 2001). The international attractiveness of university sectors relates to various performance indicators encompassing inputs and outputs of single higher education systems (e.g. percentage of foreign students as well as researchers, funding and staff capacities, student and academic mobility, drop out rates, duration of study).

Hypothesis 3a (similarity of policy-specific problem pressure) The more similar problem pressure regarding higher education in $n$ countries, the more their higher education policies will converge under the influence of the Bologna Process.

Second, the more similar the socioeconomic structures of the signatory countries are, the more likely it is that reforms in higher education will follow an analogous pathway. This fact refers to the expectation that countries sharing socioeconomic characteristics are facing similar political problems so that the likelihood for adopting the same policies increases (Lenschow et al. 2005, p. 802). Often general structural indicators like the status of economic development (e.g. cross-domestic product) are considered, while for transfer of higher education policies especially knowledge-based factors like human resources and their educational background, the technical infrastructure and the development of high-tech industries or the expenditure on education should be taken into account (OECD 1996; UNESCO 2003).

Hypothesis 3b (similarity of socioeconomic structures) The more similarity between the socioeconomic structures in $n$ countries, the more their higher education policies will converge under the influence of the Bologna Process. 
The impact of country-specific variables on delta convergence

What kind of theoretical expectations can we formulate if we are talking about convergence regarding the approximation towards an ideal policy model developed within the Bologna framework (delta convergence)? The analysis of delta convergence does not apply to groups of countries as is the case when analysing sigma convergence. Rather delta convergence deals with the direction of policy convergence towards a concrete model. With respect to the Bologna Process this incorporates specific frameworks and action lines for realising the EHEA like the Standards for European Quality Assurance as well as a Framework for Qualifications (Bergen-Communiqué 2005). Because of this altered point of view we have to formulate different hypotheses concerning the role of cultural, institutional and socioeconomic factors. We basically focus on country-specific characteristics that might enhance or impede the domestic impact of the Bologna Process (see Fig. 3). ${ }^{8}$

\section{Cultural characteristics}

To formulate expectations about the influence of cultural factors regarding delta convergence we fall back on different families of nations concerning the adaptation and implementation of EU-requirements. We tie up to the classification of three "Worlds of Compliance" (Falkner et al. 2005). ${ }^{9}$ According to this approach, it is possible to name three cultural patterns of compliance. The "World of Law Observance" is characterized by cultural conventions leading to a complete and swift implementation of European laws and guidelines, regardless of opposing domestic opportunity structures and interest constellations (Knill and Lehmkuhl 2002). In countries belonging to the "World of Domestic Politics" the adoption to European guidelines remains a function of domestic interest constellation, mainly preferences of national governments and of the most important pressure groups. The third family of nations has been described as "World of Neglect". In contrast to the other cultures of compliance the influence of national actors pushing for the implementation of European policies is the lowest-at least from a cultural point of view. Domestic problems and interests are considered to have higher priority and European norms and rules are only seriously considered if supranational actors like the European Commission are intervening (e.g. by lurking with infringement procedures). The pattern of compliance is therefore most pronounced in the "World of Law Observance" whereas the actual results in the other two cultures depend on additional factors. To be sure, one has to expect that the potential for complying to European norms and rules is higher in the "World of Domestic Politics" than in the "World of Neglect" as the former is not characterized by a cardinal disposition against European policies.

Hypothesis 4 (culture of compliance) Countries belonging to the "World of Law Observance" will converge to a higher degree towards the policy model communicated within the Bologna Process than countries from the "World of Neglect" or the "World of Domestic Politics". Countries belonging to the "World of Domestic Politics" will converge to a higher degree towards the policy model communicated within the Bologna Process than countries from the "World of Neglect".

\footnotetext{
${ }^{8}$ See footnote seven.

${ }^{9}$ Note that the underlying findings are based on the implementation of EU-directives when testing this hypothesis.
} 


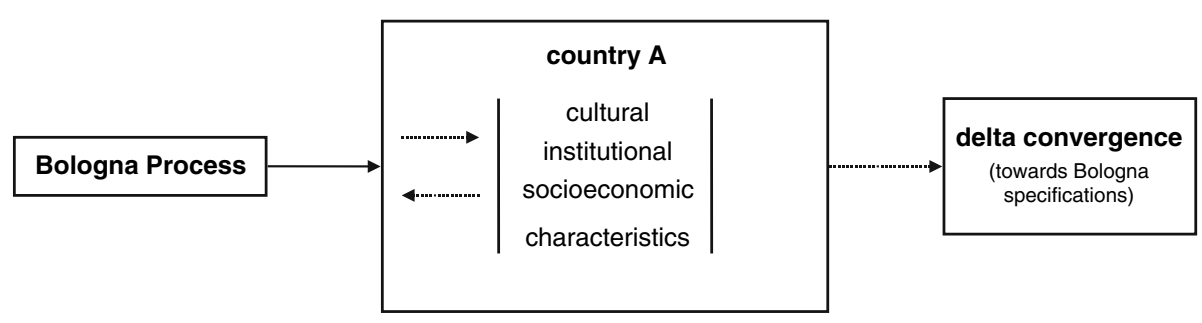

Fig. 3 Analytical framework on delta convergence

Institutional characteristics

The convergence towards a specific policy model implies a corresponding national policy change. Therefore it seems obvious to consider the role of veto players for explaining the differential impact of the Bologna Process. Veto players themselves neither cause policy change (Tsebelis 2002, p. 32) nor policy convergence, but influence the probability for actually implementing the (non-binding) arrangements communicated within the framework of the Bologna Process. Veto players are actors that are able to formally influence or block laws or amendments (Tsebelis 1995, 2002). Individual actors might be presidents, at least if they have formal decision-making power. Collective veto players refer to organisations consisting of individuals, but other than individual actors their veto power can only be carried out collectively (e.g. chambers of parliament or governing parties). Tsebelis also distinguishes between institutional and partisan veto players depending on the source of their veto power.

The probability for policy change depends on the characteristics of a country's institutional system: the number of veto players, their ideological and policy-specific distances as well as the cohesion within the (collective) veto players (i.e. the internal homogeneity of ideological and policy-specific distances) (Tsebelis 1995, p. 293, 2002, p. 2). The probability for policy change-and correspondingly policy convergence-decreases with a rising number of veto players, a growing ideological and policy-specific distances, as well as a high (or even increasing) cohesion. Crucial for determining the actual number of veto players is the so-called absorption rule (Tsebelis 2002, p. 26). As Tsebelis also considers the ideological and policy-specific distances between veto players he does not simply count the number of veto players. Instead he counts two (institutional) veto players as one, if they both may have veto power but this does not affect policy outputs because they share policy preferences. Bicameral systems, for instance, only count as two veto players if there are different majorities in both chambers. Likewise in cases of coalition governments only the ideological and policy-specific distances have to be considered.

Hypothesis 5a (veto players) The smaller the number of veto players in a country, the more its higher education policies will converge towards the policy model communicated within the Bologna Process.

Apart from the number of veto players we have to consider the distance among the veto players. Usually expert surveys have been applied to locate the ideological positions of parties (Laver and Hunt 1992) but the analysis on actors' distances also has to cover the partisan position on higher education policy (Steunenberg 2007; Tsebelis 2002, ch. 8).

Hypothesis $5 \mathbf{b}$ (veto players) The smaller the number of veto players in a country and the lower their ideological and policy preference distance respectively, the more 
its higher education policies will converge towards the policy model communicated within the Bologna Process.

Apart from analysing veto player constellations, studies on Europeanization stress the importance of preferences and beliefs of national governments for explaining delta convergence (Mastenbroek and Keulen 2006; Treib 2005). Presiding from national policy preferences would risk disregarding the case of national actors using Bologna for their purposes (Hackl 2001; Martens and Wolf 2006). Especially the beginning of the process is associated with the notion of the Bologna Process as being a "window of opportunity" (Kingdon 1984) giving national governments an instrument at hand to circumvent deadlocks and to facilitate national reforms. Furthermore the significance of national actors like the governments of the signatory states or the responsible departments typifies in concrete actions for implementing the objectives at the national level, e.g. by creating the necessary juridical framework (Luijten-Lub et al. 2004, p. 270). Just like we expect that similar policy specific preferences in the signatory countries are leading to sigma convergence (hypothesis 2b), we suppose a higher degree of delta convergence the more the preference of national governments at the beginning of the Bologna Process match the European policy model.

Hypothesis 6 (policy preferences of national governments) The more the government's preferences of a country regarding higher education policy match the guidelines defined within the Bologna Process, the more likely it is that its higher education policies will converge towards the policy model communicated within the Bologna Process.

\section{Socioeconomic characteristics}

For the analysis of sigma convergence we focused on similarities in socioeconomic structures and problem constellations (hypothesis $3 \mathrm{a}$ and $\mathrm{b}$ ). To answer the question, if and to what degree socioeconomic factors lead to a convergence towards the Bologna subjects we need to consider the degree of problem pressure. As already mentioned countries facing economic and similar policy-specific vulnerability generally adapt to European policies more easily (Schmidt 2002, p. 898). Thus we can expect an increased domestic problem pressure to trigger the transfer of higher education policies within the framework of the Bologna Process (Witte 2006, p. 93) - particularly as the Bologna Process describes a platform for disseminating best practices.

Hypothesis 7a (degree of policy-specific pressure) The higher the problem pressure in higher education policy in a country, the more likely it is that its higher education policies will converge towards the policy model communicated within the Bologna Process.

The pressure for adoption and transfer of external models and policies does not only entail specific problems regarding higher education like a low international competitiveness but may also result from general problems restricting the state's capacities to solve policy problems (Scharpf 1997). This includes economic and fiscal factors like public debts, the financial situation of universities or high unemployment rates.

Hypothesis $\mathbf{7 b}$ (degree of socioeconomic problem pressure) The higher the socioeconomic problem pressure in a country, the more likely it is that its higher education 
policies will converge towards the policy model communicated within the Bologna Process.

\section{Conclusion}

This paper deals explicitly with the so-called Bologna Process and its impact on crossnational policy convergence. Based on insights from political science and studies dealing with Europeanization and international policy convergence we map various factors affecting the impact of convergence mechanisms. Starting with the assumption that the Bologna Process can be essentially conceptualized as a process of transnational communication we developed a research design that integrates different cultural, institutional, and socioeconomic factors to explain the differential impact of the Bologna Process.

The central the purpose of the paper is to serve as a starting point for future researchnot only as a guide for more comprehensive, systematic and comparative empirical work on higher education, but also for further theoretical (and perhaps methodological) reasoning concerning research on higher education policy. This trend towards greater methodological and theoretical stringency is particularly evident in a number of publications of the Centre for Higher Education Policy Studies showing that testing hypotheses can be a fruitful endeavour in higher education analysis (e.g. Theisens 2004; Witte 2006). Further comprehensive studies, incorporating a wider range of theories, methods, and cases, are however still needed. As the purpose of this paper is to prepare the grounds for a systematic test of various hypotheses on the differential impact of the Bologna Process in a comparative research design, we believe that we have considered theoretical assumptions suitable to such an approach.

To be sure, our way of dealing with the described research questions and the deficits inherent in research on higher education policy is certainly not a miracle cure, in particular because the actual benefits of our conceptual paper have yet to be demonstrated in an empirical analysis. Also readers have to be aware of the certainly existing limitations of a variable orientated approach (Aus 2005). For example it seems not feasible to test the causal mechanisms underlying our hypotheses. We are merely able to investigate causes and effects, but we can not dissect the exact causal mechanisms underlying the Bologna Process. Investigating the causal chains themselves (and formulating correspondent hypothesis) requires more dynamic qualitative techniques such as process tracing.

Moreover, we did not discuss the issue of case selection-a very important questions for carrying out comparative studies. As we proposed to test competing theoretical explanations we recommend to follow Lijphart's comparable cases strategy (1971, 1975). This means that—just like in most similar-systems designs (Przeworski and Teune 1970)—we sample countries that are different on the hypotheses we like to test, but are similar in as many additional variables as possible that might also have an impact on the outcome to be explained. This helps to ensure the comparability of the countries and to control for factors that might be of relevance too. Furthermore, this strategy should be best to falsify our hypothesis-without variance on a potentially independent variable we would not be able to cover variance on the variable to be explained. However, methodological issues like case selection also depend on the techniques researchers are using for carrying out a comparative study. Even if one is dealing with mostly qualitative data as it is the case in higher education policy one can figure out a wide range of techniques for conducting a comparative analysis in social sciences (Moses et al. 2005). This does not only encompass 
comparative case studies but ranges from discrete statistical techniques (like logit modelling) to more recent macro-qualitative approaches as Qualitative Comparative Analysis (QCA). Our central aim is to provide a construction kit for analysing policy convergence within the context of the Bologna Process (one does not have to test the full range of variables discussed) rather than prescribing a distinct methodological approach. While the operationalization of variables and collecting appropriate data need original and careful inquiry, going into detailed discussion of these issues would go certainly beyond the scope of this article.

Nevertheless, we believe that our proposal offers several distinct advantages over most of the previous approaches to analyze changes in higher education policy. First, our approach integrates fruitful concepts of policy analysis in order to better grasp the interaction of explanatory factors. This was exemplified by the incorporation of theoretical explanations from Europeanization and convergence theories. Second, it includes both national and international factors to explain policy convergence in higher education. Third, the research design is very specific about its empirical and theoretical scope, i.e. the Bologna Process and national conditions influencing the national impact of transnational communication. Often studies fail to theoretically clarify the causal mechanisms to be examined or mix various convergence mechanisms under the abstract heading of Internationalization, Globalization or Europeanization. Fourth, in relying on testable hypotheses it should be possible to conduct a truly comparative analysis of more than just a few cases. Fifth, the application of the research design will offer us more insights into the relationship between the considered independent variables, so we can systematically integrate the different theoretical arguments in an interactive model (Braun and Gilardi 2006; Braun et al. 2007). Sixth, accomplishing the proposed research design does not only tell us what national factors account for the differential impact of the Bologna Process. It should also help us to give a systematic answer to the question if and to what degree we can observe convergence/divergence in higher education in the course of the Bologna Process. In this respect, our research design might already give us a preliminary answer on the issue of fragmentation. Just as the official documents provided in the Bologna Process remain quite unspecific on the "degree of convergence and the dimensions to which it shall extend" (Witte 2006, p. 4), the research design implicitly carries this notion by the diversity of conditional variables that have been discussed. In the light of the theoretical discussion we should therefore not expect to find convergence in every detail but rather on a system level. And still, as Vught puts it: "[...] it is time that we-in higher education research-do a sort of a next version of Burton Clark's 'Higher Education System', but about higher education system dynamics [...] identifying the crucial variables and their relationships that explain why higher education systems operate as the do" (CHEPS 2005, p. 4). Perhaps our thoughts can become a part of this endeavour.

Acknowledgements An earlier version of this article has been presented at the European Consortium for Political Research Joint Sessions of Workshops in Helsinki 2005. The authors thank the conference paper discussants and anonymous reviewers for helpful suggestions.

\section{References}

Almond, G. A., \& Powell, G. B. (1966). Comparative politics. A development approach. Boston: Little, Brown and Company.

Altbach, P. G. (1998). Comparative perspectives on higher education for the twenty-first century. Higher Education Policy, 11, 347-356. 
Aus, J. P. (2005). Conjunctural causation in comparative caseoriented research. Exploring the scope conditions of rationalist and institutionalist causal mechanisms. ARENA-Centre for European Studies, Oslo (ARENA Working Papers WP 28/2005).

Bennett, C. J. (1991). What is policy convergence and what causes it? British Journal of Political Science, 21(2), 215-233.

Bergen-Communiqué (2005). The European higher education area-communiqué of the conference of European ministers responsible for higher education. Bergen, 19th-20th May.

Beukel, E. (2001). Educational policy. Institutionalization and multi-level governance. In S. Andersen \& K. Eliassen (Eds.), Making policy in Europe (pp. 124-139). London: Sage.

BFUG (2005). Bologna Process stocktaking. Report from a working group appointed by the Bologna Follow-up Group to the Conference of European Ministers Responsible for Higher Education, Bergen, 19th-20th May 2005. Bologna Follow-up Group (BFUG), Bergen.

Bleiklie, I. (2001). Towards European convergence of higher education policy? Higher Education Management, 13(3), 9-29.

Bologna-Declaration (1999). The European higher education area. The Bologna declaration of 19 June 1999. Joint declaration of the European Ministers of Education.

Braun, D., \& Gilardi, F. (2006). Taking 'Garlton problem' seriously. Towards a theory of policy diffusion. Journal of Theoretical Politics, 18(3), 298-322.

Braun, D., Gilardi, F., Flüglister, K., \& Luyet, S. (2007). Ex pluribus unum: Integrating the different strands of policy diffusion theory. In K. Holzinger, C. Knill, \& H. Jörgens (Eds.), Transfer, Diffusion und Konvergenz, von Politiken (pp. 39-55). Wiesbaden: VS Verlag.

Castles, F. (1994). On religion and public policy: Does Catholicism make a difference? European Journal of Political Research, 25, 19-40.

Cerych, L. (2002). Sorbonne, Bologna, Prague: Where do we go from here? In J. Enders \& O. Fulton (Eds.), Higher education in a globalising world. International trends and mutual observations (pp. 121-126). Dordrecht: Kluwer Academic Publishers.

Checkel, J. T. (2000). Compliance and conditionality. ARENA-Centre for European Studies, Oslo (ARENA Working Papers WP 00/18).

CHEPS (2005). The cheps unplugged interview series. Frans van Vught. Cheps Unplugged. An Essential Newsletter, 5(2), 4-5.

Clark, B. R. (1983). The higher education system. Academic organization in cross-national perspective. Berkeley: University of California Press.

Dill, D., \& Sporn, B. (Eds.) (1995). Emerging patterns of social demand and university reform: Through a glass darkly. Oxford Pergamon.

Drezner, D. W. (2001). Globalization and policy convergence. International Studies Review, 3, 53-78.

Enders, J. (2002). Higher education, internationalisation, and the nation-state. German Policy Studies, 2(3), $1-33$.

Esping-Andersen, G. (1990). Three worlds of welfare capitalism. Cambridge: Cambridge University Press.

Falkner, G., Treib, O., Hartlapp, M., \& Leiber, S. (2005). Complying with Europe: EU harmonisation and soft law in the member states. Cambridge: Cambridge University Press.

Feick, J., \& Jann, W. (1988). "Nations matter"-Vom Eklektizismus zur Integration in der vergleichenden Policy-Forschung? In M. G. Schmidt (Ed.), Staatstätigkeit. International und historisch vergleichende Analysen (pp. 196-220). Opladen: Westdeutscher Verlag.

Friedkin, N. E. (1993). Structural bases of interpersonal influence in groups. A longitudinal case study. American Sociological Review, 58, 861-872.

Gellert, C. (1999). The changing conditions of teaching and learning in European higher education. In C. Gellert (Ed.), Innovation and adaption in higher education (pp. 9-30). London: Jessica Kingsley Publishers.

Goedegebuure, L., \& van Vught, F. (1996). Comparative higher education studies: The perspective from the policy sciences. Higher Education, 32, 371-394.

Hackl, E. (2001). Towards a European area of higher education: Change and convergence in European higher education. European University Institute, Florence (EUI Working Paper RSC No. 2001/09).

Hall, P. A., \& Taylor, R. C. R. (1996). Political science and the three new institutionalisms. Political Studies, 44, 936-957.

Heichel, S., Pape, J., \& Sommerer, T. (2005). Is there convergence in convergence research? An overview of empirical studies on policy convergence. Journal of European Public Policy, 12(5), 817-840.

Heidenreich, M. (2003). Die Debatte um die Wissensgesellschaft. In S. Böschen \& I. Schulz-Schaeffner (Eds.), Wissenschaft in der Wissensgesellschaft (pp. 25-51). Opladen: Westdeutscher Verlag.

Héritier, A., \& Knill, C. (2001). Differential responses to European policies: A comparison. In A. Héritier, D. Kerwer, C. Knill, D. Lehmkuhl, M. Teutsch, \& A.-C. Douillet (Eds.), Differential Europe. The 
European union impact on national policymaking (pp. 257-294). Lanham: Rowman \& Littlefield Publishers.

Hogwood, B. W., \& Peters, G. B. (1983). Policy dynamics. New York: St. Martin Press.

Holzinger, K., \& Knill, C. (2005). Causes and conditions of cross-national policy-convergence. Journal of European Public Policy, 12(5), 775-796.

Holzinger, K., \& Knill, C. (2007). Ursachen und Bedingungen internationaler Politikkonvergenz. In K. Holzinger, C. Knill, \& H. Jörgens (Eds.), Transfer, Diffusion und Konvergenz von Politiken (pp. 85-107). Wiesbaden: VS Verlag.

Holzinger, K., Knill, C., \& Jörgens, H. (Eds.) (2007). Transfer, Diffusion und Konvergenz von Politiken. Wiesbaden: VS Verlag.

Huisman, J., \& van der Wende, M. (2004). The EU and Bologna: Are supra- and international initiatives threatening domectic agendas? European Journal of Education, 39(3), 349-357.

Inglehart, R. (1989). Kultureller Umbruch. Wertwandel in der westlichen Welt. Frankfurt a.M.: Campus.

Kerr, C. (1983). The future of industrial societies: Convergence or continuing diversity? Cambridge: Harvard University Press.

Kingdon, J. W. (1984). Agendas, alternatives, and public policies. New York: HarperCollins.

Knill, C. (2001). The Europeanisation of national administrations. Cambridge: Cambridge University Press.

Knill, C. (2005). Introduction: Cross-national policy-convergence: Concepts, approaches and explanatory factors. Journal of European Public Policy, 12(5), 764-774.

Knill, C., \& Lehmkuhl, D. (2002). The national impact of EU regulatory policy: Three Europeanization mechanisms. European Journal of Political Research, 41(2), 255-280.

Kohler-Koch, B. (1999). The evolution and transformation of European governance. In B. Kohler-Koch \& R. Eising (Eds.), The transformation of governance in the European Union (pp. 14-35). London: Routledge.

Laver, M., \& Hunt, W. B. (1992). Policy and party competition. London: Routledge.

Lenschow, A., Liefferink, D., \& Veenman, S. (2005). When the birds sing. A framework for analysing domestic factors behind policy convergence. Journal of European Public Policy, 12(5), 797-816.

Lijphart, A. (1971). Comparative politics and the comparative method. American Political Science Review, 65(3), 682-693.

Lijphart, A. (1975). The comparable-cases strategy in comparative research. Comparative Political Studies, $8(2), 158-175$.

Luijten-Lub, A., Kontogiannopoulou-Polydorides, G., van der Wende, M., \& Williams, G. (2004). International comparative analysis. In J. Huisman \& M. van der Wende (Eds.), On cooperation and competition. National and European policies for the internationalisation of higher education (pp. 249275). Bonn: Lemmens.

Luijten-Lub, A., van der Wende, M., \& Huisman, J. (2005). On cooperation and competition: A comparative analysis of national policies for internationalisation of higher education in seven Western European countries. Journal of Studies in International Education, 9(2), 147-163.

Martens, K., Balzer, C., Sackmann, R., \& Weymann, A. (2004). Comparing governance of international organizations-The EU, the OECD and educational policy. University of Bremen, Collaborate Research Centre 597, Bremen (TranState Working Papers 7).

Martens, K., \& Wolf, K. D. (2006). Paradoxien der Neuen Staatsräson. Die Internationalisiserung der Bildungspolitik in der EU und der OECD. Zeitschrift für Internationale Beziehungen, 13(2), 145-176.

Mastenbroek, E. (2005). EU compliance: Still a 'black hole'? Journal of European Public Policy, 12(6), 1103-1120.

Mastenbroek, E., \& van Keulen, M. (2006). Beyond the goodness of fit. A preference-based account of Europeanization. In R. Holzhacker \& M. Haverland (Eds.), European research reloaded: Cooperation and integration among Europeanized states (pp. 19-42). Dordrecht: Springer.

Mayntz, R., \& Scharpf, F. W. (Eds.) (1995). Gesellschaftliche Selbstregelung und politische Steuerung. Frankfurt a.M.: Campus Verlag.

McLendon, M. K. (2003). The politics of higher education: Toward an expanded research agenda. Educational Policy, 17(1), 165-191.

Moses, J., Rihoux, B., \& Kittel, B. (2005). Mapping political methodology: Reflections on a European perspectice. European Political Science, 4, 55-68.

Nagel, A.-K. (2006). Der Bologna-Prozess als Politiknetzwerk. Akteure, Beziehungen, Perspektiven. Wiesbaden: DUV Verlag.

Neave, G. (2003). The Bologna declaration: Some of the historic dilemmas posed by the reconstruction of the community in Europe's systems of higher education. Educational Policy, 17(1), 141-164.

OECD (1996). The knowledge-based economy. Paris: Organisation for Economic Co-operation and Development (OECD). 
Przeworski, A., \& Teune, H. (1970). The logic of comparative social inquiry. New York: Wiley.

Scharpf, F. W. (1997). Introduction: The problem-solving capacity of multi-level governance. Journal of European Public Policy, 4, 520-538.

Schimank, U., \& Stölting, E. (Eds.) (2001). Die Krise der Universitäten. Wiesbaden: Westdeutscher Verlag.

Schmidt, V. A. (2002). Europeanization and the mechanics of economic policy adjustment. Journal of European Public Policy, 9(6), 894-912.

Seibel, W. (1997). Historische Analyse und politikwissenschaftliche Institutionenforschung. In A. Benz \& W. Seibek (Eds.), Theorieentwicklung in der Politikwissenschaft - eine Zwischenbilanz (pp. 357-376). Baden-Baden: Nomos.

Simmons, B. A., \& Elkins, Z. (2004). The globalization of liberalization: Policy diffusion in the international political economy. American Political Science Review, 98, 171-189.

Slaughter, S. (2001). Problems in comparative higher education: Political economy, political sociology and postmodernism. Higher Education, 41, 389-412.

Steinmo, S., \& Thelen, K. (1992). Historical institutionalism in comparative politics. In S. Steinmo, K. Thelen, \& F. Longstreth, (Eds.), Structuring politics. Historical institutionalism in comparative analysis (pp. 1-33). Cambridge: Cambridge University Press.

Steunenberg, B. (2007). A policy solution to the European Union's transposition puzzle: Interaction of interests in different domestic arenas. West European Politics, 30(1), 23-49.

Strang, D., \& Meyer, J. W. (1993). Institutional conditions for diffusion. Theory and Society, 22, 487-511.

Teichler, U. (1996). The changing nature of higher education in Western Europe. Higher Education Policy, 9(2), 89-111.

Tews, K. (2002). Der Diffusionsansatz für die vergleichende Policy-Analyse. Wurzeln und Potenziale eines Konzeptes. Eine Literaturstudie. Forschungsstelle für Umweltpolitik. Freie Universität Berlin, Berlin (FFU-report 02-2002).

Theisens, H. C. (2004). The state of change. Analysing policy change in Dutch and English higher education. Enschede: Centre of Higher Education Policy Studies (CHEPS).

Treib, O. (2005). Die Bedeutung der nationalen Parteipolitik für die Umsetzung europäischer Sozialrichtlinien. Frankfurt a.M.: Campus Verlag.

Tsebelis, G. (1995). Decision making in political systems: Veto players in presidentialism, parliamentarism, multicameralism and multipartism. British Journal of Political Science, 25, 289-325.

Tsebelis, G. (1999). Veto-players and law production in parliamentary democracies: An empirical analysis. American Political Science Review, 93(3), 591-608.

Tsebelis, G. (2002). Veto players: How political institutions work. Princeton: Princeton University Press.

UNESCO (2003). Measuring and monitoring the information and knowledge societies: A statistical challenge. Paris: United Nations Educational, Scientific and Cultural Organization (UNESCO).

Vaira, M. (2004). Globalization and higher education organizational change: A framework of analysis. Higher Education, 48, 483-510.

van der Wende, M. (2001). The international dimension in national higher education policies: What has changed in Europe in the last five years? European Journal of Education, 36(4), 431-441.

van der Wende, M., \& Huisman, J. (2003). The role of Europe in higher education policy: Expansion across borders and levels. Tijdschrift voor Hoger Onderwijs, 21(1), 30-47.

van Vught, F., van der Wende, M., \& Westerheijden, D. (2002). Globalisation and internationalisation: Policy agendas compared. In J. Enders \& O. Fulton (Eds.), Higher education in a globalising world. International trends and mutual observations (pp. 103-120). Dordrecht: Kluwer Academic Publishers.

Veiga, A. (2005). Europeanization of higher education area: Towards a framework of analysis. Paper presented at the 2nd EUREDOCS Conference "Transformations of higher education and research policies, systems and institutions in European countries", Bergen, May 20th-21st.

Veiga, A., \& Amaral, A. (2006). The open method of coordination and the implementation of the Bologna process. Tertiary Education and Management, 12(4), 283-295.

Walter, T. (2006). Der Bologna-Prozess. Ein Wendepunkt europäischer Hochschulpolitik? Wiesbaden: VS Verlag für Sozialwissenschaften.

Welsh, H. A. (2004). Higher education in Germany: Reform in incremental steps. European Journal of Education, 39(3), 359-375.

Witte, J. (2004). The introduction of two-tiered study structures in the context of the Bologna Process: A theoretical framework for an international comparative study of change in higher education systems. Higher Education Policy, 17, 405-425.

Witte, J. (2006). Change of degrees and degrees of change. Comparing adaptions of European higher education systems in the context of the Bologna Process. Enschede: Center for Higher Education Policy Studies (CHEPS), University of Twente. 